\title{
Unconditional respect: change of mindset for effective and safe policing
}

\begin{abstract}
This article on unconditional respect is primarily based on a case study of the 1910 Squad, Kansas City, Missouri Police Department. Law enforcement has always been complicated and hazardous. That is as true today as at any time in history. Even so, policing rests on Sir Robert Peel's "Nine Principles" dictating that the ultimate mission of policing is to build high trust relationships instead of drawing lines of distinction between police and public. The goal of this article is to show that there is a method whereby it is possible to be effective with regard to the standard monitoring of law enforcement and at the same time build trust. The article is built on the philosophy of unconditional respect exercised by the 1910 Squad, Kansas City, Missouri Police Department. Erase the rest of the sentence. It will point out factors leading to effectiveness and trust within a community and share an example of how this method is used in practice. Respect is a very important element in our society and our interpersonal relations, and its presence or absence largely determines how we relate to one another and society at large. Moreover, respectful treatment of others on the part of authority figures increases general levels of commitment and rule compliance. Three steps;
a. See people as people.
b. Accept the ways police are part of the problem.
c. Focus on new ways of being helpful and responsive are introduced. In conclusion the results of the method will be introduced.

Keywords: policing, police, respect, unconditional respect, leadership
Volume 5 Issue 5 - 2017

\author{
Ann Christine Andersson Arnten \\ Department of National Operations, Swedish Police, Sweden
}

Correspondence: Ann Christine Andersson Arnten, Swedish Police, Department of National Operations, Assessment Functions, 10226 Stockholm, Sweden, Tel 722027660;

Email acarnten@gmail.com

Received: August 29, 2017 | Published: November 14, 2017

\section{Introduction}

Law enforcement is a challenging and necessary social undertaking. Moreover, the political language of the western world has become increasingly polarized. As "us against them" becomes prevalent in public discourse, it reintroduces the west to phrases such as; "the war on...' President Richard Nixon used war language in June 1971 when he introduced the 'war on drugs'. ${ }^{1}$ Nevertheless, policing is not synonymous with armed conflict, and drawing a sharp line between police and citizens is not an effective means for building trust and shared goals. ${ }^{2}$ Describe the current crossroads of western policing, which is the balance between change of culture and transforming police training with the goal of developing positive police contact that facilitates public confidence. The basic philosophy of British policing, known as Sir Robert Peel's Nine Principles of Policing were introduced to every new officer from 1829 as a general instruction and included. ${ }^{3}$

i. To prevent crime and disorder, as an alternative to their repression by military force and severity of legal punishment.

ii. To recognise always that the power of the police to fulfil their functions and duties is dependent on public approval of their existence, actions and behaviour and on their ability to secure and maintain public respect.

iii. To recognise always that to secure and maintain the respect and approval of the public means also the securing of the willing cooperation of the public in the task of securing observance of laws.

iv. To recognise always that the extent to which the co-operation of the public can be secured diminishes proportionately the necessity of the use of physical force and compulsion for achieving police objectives.

v. To seek and preserve public favour, not by pandering to public opinion; but by constantly demonstrating absolutely impartial service to law, in complete independence of policy, and without regard to the justice or injustice of the substance of individual laws, by ready offering of individual service and friendship to all members of the public without regard to their wealth or social standing, by ready exercise of courtesy and friendly good humour; and by ready offering of individual sacrifice in protecting and preserving life.

vi. To use physical force only when the exercise of persuasion, advice and warning is found to be insufficient to obtain public cooperation to an extent necessary to secure observance of law or to restore order, and to use only the minimum degree of physical force which is necessary on any particular occasion for achieving a police objective.

vii. To maintain at all times a relationship with the public that gives reality to the historic tradition that the police are the public and that the public are the police, the police being only members of the public who are paid to give full time attention to duties which are incumbent on every citizen in the interests of community welfare and existence.

viii. To recognise always the need for strict adherence to policeexecutive functions, and to refrain from even seeming to usurp the powers of the judiciary of avenging individuals or the State, and of authoritatively judging guilt and punishing the guilty. 
ix. To recognise always that the test of police efficiency is the absence of crime and disorder, and not the visible evidence of police action in dealing with them.

x. Peelian-style policing draws no dramatic lines of distinction between police and public. Nevertheless, reflecting upon these principles, it is clear that the ultimate mission of policing is to build high-trust relationships with all individuals and groups within a given community. The penultimate mission is to leverage these high-trust relationships to infuse communities with safety, security, and prosperity. ${ }^{4}$ In 2012 (GOV.UK,), the Home Office described this approach as "the power of the police coming from the common consent of the public, as opposed to the power of the state. It does not mean the consent of an individual". The Home Office also added an additional statement to the Peelian principles: "No individual can choose to withdraw his or her consent from the police, or from a law." These same values are reflected today in the recent. ${ }^{5}$ The task force report is organized around six main topic areas or "pillars" -- all geared towards generating community safety and security within a respectful context of interaction and exchange. The report calls for a shift in professional identity or self-image of police officers from that of a warrior to that of a "guardian, and the report requires the use of procedural justice principle to guide all police-citizen interactions.

The four central principles of procedurally-just behaviour are outlined in the report:

a. Treating people with dignity and respect,

b. Giving individuals "voice" during encounters

c. Being neutral and transparent in decision making, and

d. Conveying trustworthy motives.

These principles can be viewed as attributing to people the propensity to "do the right thing" and is based on viewing all people as more alike than different. Research indicates that many traditional policing practices have proven less than effective. ${ }^{6,7}$ Among the traditional and often highlighted work methods are 'zero-tolerance' and 'stop-and-frisk'. Zero-tolerance is based on the ideas to 'nip things in the bud' focusing on the smaller offences and reducing petty crime and thereby "creating an environment less hospitable to more serious criminals' ${ }^{8}$ Officers on the street are instructed to approaches citizens according to the above criteria. The method of 'stop-andfrisk' is based on well-established and legally precedents. But, the new meaning of the method practiced for instance in New York include a more increased frequency and are often located to high crime areas with the goal to promote officers safety and reduce crime. The theory behind the method is that when there is an increased likelihood to be stopped by the police the less likely the individual is to commit crime. ${ }^{9}$ Unfortunately, both of these methods are based on interactions between police and citizens, where increased frequency, that may be construed as more negative than positive. Research and history have demonstrated that the long-term costs of methods like 'zero-tolerance' and 'stop-and-frisk' are high in comparison to purported gains. ${ }^{6}$

Among the expenses of such measures may be counted: harm of police-community relations, diminished trust along with disruptions to community safety. ${ }^{8,10,11}$ Some individuals in policing find these tactics lack utility. ${ }^{4}$ On the other hand, research evidence does support continued investments in police innovations that call for greater focus and tailoring of police efforts, combined with an expansion of the toolbox of policing beyond mere law enforcement. ${ }^{7}$ Wesiburd et al. ${ }^{4}$ argue that hot spot policing, with geographical focus, and problemoriented policing (POP) are more effective than zero tolerance and stop and frisk tactics. Problem-oriented policing focuses upon and analyzes the local problems and provides for tailored actions to address root causation. With POP, the interaction between police and citizens are specifically related to the situation and individuals in focus. Within POP the more sweeping police encounters, increasing the risk of including non criminal individuals, that are associated with zero-tolerance and stop-and-frisk are replaced with more selective actions and interaction. Another method that has shown positive results is the use of dialogue-based policing, a method for management of protest events, which comprises flexibility and reflexion, as well as prevention. ${ }^{12,13}$ This method is dependent upon facilitating a continuous channel of communication-based trust, between protesters and police. ${ }^{14}$

In dialogue-based policing, the officers, as stated in the name, are to keep an open contact with protesters. The dialogue is aimed to build a relation that facilitates trust and in the end a certain amount of self-policing among the protesters. Moreover, when a trustful contact is created between the police and the protesters, information about negatively behaving individuals are passed over to the police by the protesters. By using the two above-mentioned methods of policing (problem-oriented policing and dialogue-based policing), the police facilitate a more positive contact between the officers and the citizens. Through a more outreaching Peelian-style behaviour by officers trust is build and approval of their work is gained and thereby potential of future cooperation with the citizens. These described methods of POP and dialogue-based policing demonstrate that there are effective methods that work hand-in-hand with Peel's nine-principles.

\section{Respect}

Respect presents a very important element in our society and our interpersonal relations and, as pointed out by Lawrence ${ }^{15}$, it could be looked upon as "the single most important ingredient in nourishing relationships and creating a just society" (p. 13). Respect encompasses both how we relate to others (accepting and caring) and how we relate to society (adherence to rules and social power). ${ }^{16}$ Research indicates that greater respect among adolescents towards authority figures, such as police officers, is associated with lower levels of aggression and other forms of antisocial behaviour. ${ }^{17,18}$ Moreover, respect-oriented treatments exerted by authority augment commitment and rule compliance. ${ }^{19}$ The ultimate goal regarding respect within interpersonal relations pertains to the notion of mutual respect. However, this is unfortunately not always the case when it comes to interactions between the police and the public. The philosophy of unconditional respect implies that the responsibility for engendering respect during interactions between the police and the public be placed on the representatives of law enforcement. It dictates that those in authority (police) should demonstrate respect for others independent of any reciprocation on the part of the public. Unconditional respect focuses on the respect due each person by virtue of their humanity. It involves the recognition of personal integrity and every individual's personal status as an autonomous, rational agent (actor). ${ }^{20}$

\section{The method involving "unconditional respect"}

The above-cited research on policing establishes what appears 
obvious to many observers, i.e., that policing methods that leverage relational contact with the public have been proven effective. As demonstrated, policing methods characterized by positive contacts with the public are more effective than that of those that focus solely on "law enforcement." Indeed, policing strategies that focus exclusively on routine law enforcement functions have been shown to be more costlier in the long run. When deciding to implement unconditional respect in the context of day-to-day policing, it is essential such strategy be rooted in the appropriate shift in mindset. This alteration of mindset implies a metamorphosis from the dichotomous and static "us against them," with a point of departure that includes three steps. ${ }^{21}$

\section{See others}

This step involves the primary stage of viewing 'people as people', rather than objects, in combination with a genuine respect for their humanity. Although seemingly obvious and straightforward, cultivating the ability, or even inclination, to see 'people as people' is neither simple nor straightforward. One ought to be aware that police officer's daily experience is fraught with 'evidence' that many members of the public are morally and, 'intellectually inferior' (try watching an episode of COPS). Once this rationalization becomes a general attitude, it becomes a reflex action to draw justification from 'inferior' others--the perceived inferiority of others justifies seeing them and treating them as inferior. Seeing people as inferior objects fosters intentional and implicit attitudes and actions on the part of officers. These attitudes and actions tend to invite responses from others, which serve to 'justify' seeing others as inferior objects in the first place. And the cycle continues. Arbinger calls this mutually destructive cycle "Collusion." Developing the ability to terminate the justification from the so-called irritating behavior of other individuals may be a reality check on the level of the "red pill" in the Matrix (1999 Fantasy Science Fiction Film). As it turns out, people are people! People have needs, fears, burdens and objectives which motivate them. People are not mindless drones which appear to make the officer's work more complicated. Being alive and responsive to the difficulties, fears, and objectives of others (seeing them as people) are the keys to real situational awareness and thus the foundation for officer safety. ${ }^{22}$

Consider two story briefs to illustrate the power of being alive to humanity. Officer A walks in on a late-night robbery. The clerk has two weapons trained upon them, and the perpetrators threaten the clerk with theirs, and the officer's, life if they alert the officer. The officer conducts his business and leaves, oblivious to the clerk's distress and the presence of robbers armed with long guns. Officer B is doing business at a different convenience store and notices the clerk seems troubled. The clerk ends up telling the officer they just found out their brother in another state has received an upsetting medical diagnosis. Officer A is a 'good' aggressive hard working officer, but is oblivious to human realities around them. Officer B is alive and responsive to the humanity around them; officer B has taken the "red pill".

\section{Adjust efforts}

Involves finding new ways of being helpful and responsive. These are not behavioural prescriptions such as, "Do this, don't do that", etc. Unconditional respect is simply being alive and sensitive the burdens, fears and challenges weighing down people who find themselves in difficult circumstances. Then responding to the concerns of others in meaningful ways while discharging one's duties. For an example of spontaneous responsiveness, view this brief video (https://www. youtube.com/watch? $v=w M-o M p h N q d A \& t=1 s)$.

\section{Measure impact}

Measure and hold oneself accountable for the impact of one's work upon others. Formal and informal processes must be in place to verify that efforts have been helpful to others and produce the desired organizational results. It is tempting to skip this critical portion of this simple iterative three step process. However, omitting this step can be devastating. Consider how aggressive stop and frisk policies have proven to alienate and anger communities, even while the police have assumed they were delivering the results the community wanted. One agency in America has taken to issuing a "Voice of Your Community" survey after each official police contact. The purpose is to recognize the essential humanity (step one) of each person by giving them an effective voice. Then to "measure impact" (step three) of each police contact so that future efforts can be adjusted (step two). After all, each contact between police officer and cityzen is either building or destroying the very trust and collaborative spirit that is prerequisite for a safe and prosperous community.

http://www.fourstateshomepage.com/news/carthage-policedepartment-to-conduct-survey-to-improve-policing/592029258. For an example of effective feedback measures, consider the results of the following example.

\section{Unconditional respect in practice}

Unconditional respect is not just about what we do, it is about how we do it. Therefore, the change is not so much about change of methods as it is about change in attitudes and behaviour. The following is therefore to be showing how following an accepted method but changed attitudes and behaviour can give new and better results. It is based on personal interviews (2017) between Dr. Andersson Arntén and the team-leader of the 1910 Squad, veteran of over 2500 tactical operations with the Kansas City, MO Police Department. He found that 'zero-tolerance' was not effective and that its tactics exposed officers and citizens to increased hazards with meagre long-term benefit. This team-leader began to look for other ways to respond to the people his team confronted. His team began by suspending their personal judgment of others and fostering an attitude of unconditional respect for the people with whom they engaged.The SWAT team that that the team-leader was appointed to lead was comprised of intelligent officers who intended to make a difference in the community by targeting drug dealers and career criminals. The individual team members deeply resented the people they arrested, regarding them as morally deficient and fundamentally flawed. Over time, this feeling of contempt became characteristic of the team, and they directed their intolerance at most of the people with whom they interacted, regardless of whether they were involved in criminal activity. As the "us against them" mentality deepened, the team developed a disdain for police officers from other units and teams, thereby creating a caustic working relationship void of true cooperation and synergistic reinforcement. This collective perception of the public manifested itself during the day-to-day interactions with civilians. The team became the most complained on squad in the entire department. As a team leader, he was aware that the team was garnering a lot of negative attention due to the high volume of complaints, and he set out to change the way they implemented the business of law-keeping. The first step he endeavoured was to address the behaviours he assumed were driving the complaints.

\section{Doing the right thing}

It was noted that the team members were not following a policy 
that required them to leave legal paperwork at the scene of all search warrant executions. This breach of protocol generated many complaints from members of the public. Additionally, it frustrated the efforts of the detectives who had to backtrack to locate the paperwork after the fact. Under these circumstances, the officer in charge called a team meeting and issued very clear instructions, stating, "Beginning today, you will leave a copy of the search warrant and a return receipt at the scene of every warrant service. You will leave these things in plain sight where the resident can easily find them."

\section{Being a part of the problem}

One week after the team-leader issued the new edict, his team served a search warrant in one of Kansas City's more troubled neighbourhoods. Following the search of the home, the team-leader observed one of the team members pulling up a copy of the search warrant and a completed return receipt from a clipboard. The officer then walked over to where the homeowner was seated and, without looking at the man, flung the paperwork at his feet. The papers hit floor in front of the man, and the officer turned on his heels and, without saying a word, left the home. the team-leader recalls "I will never forget the look on the man's face as he stooped to pick the papers up off the floor. It was as if the officer had thrown him on the ground". Despite the frustration experienced by the team-leader, he was overcome by the realization that the officer had followed his instructions to the letter. He indeed left a copy of the requisite paperwork in plain sight where the homeowner could see it. The hurt look on the homeowner's face was occasioned not by what the officer did, but by his lack of responsiveness and courtesy when he did it. It became apparent in that moment that implementing positive change required more than merely addressing and correcting the undesirable behaviour of the team members. The only way the team could change substantively was if all concerned worked together to shift their collective mindsets and begin recognizing and responding to the humanity of the people with whom they interacted.

\section{Change of mindset}

Once the team-leader and his team began to be alive and responsive to the needs, concerns, fears and burdens of others (seeing people as people) the team's behaviour began to change rapidly. A shift from an inward mindset (where officers see others as mere objects acting upon the team) to an outward mindset (where officers see others as people with needs, fears, hopes, burdens, and objectives) precipitates many attitudinal and behavioural changes. It would be impossible and impractical to list all the changes, and that would miss the point. The point is that a shift in mindset is the single key to all behavioural changes that both serve to improve the impact upon others and further the team's mission. None-the-less, consider a couple examples for illustrative purposes. By asking and employing the statement: "What would it be like to be policed by people like us?" the team-leader invited the team members to place themselves in the position of those with whom they had contact during warrant service operations, thereby adopting an 'outside perspective.' This mental exercise led to deeper conversations about the differences between behaviour and mindset. Initially, the team members presented justifications for the way they approached their jobs; however, after much debate and critical thinking, the team conceded that the only thing that could have a lasting impact on the way they were perceived (by the public and their fellow department members) was a shift in the way they viewed themselves in relation to their jobs and the people they served.

\section{Change of behaviour}

Once the team began to reformulate their roles and the way they saw certain members of the public, the prevailing situation began to improve almost immediately. Many of the friction points that existed between the team and other department elements also rescinded. The team began considering the impact of their work on other police officers and partner agencies. They worked to uncover the objectives of their co-workers and structured their work in a way that would help facilitate their co-workers' objectives. By recognizing that those in the community were people who had a vested interest in how they were policed, the behavioural changes made by the team were rendered impactful and transformative. For example, internal to the organization, the team-leader team found new ways to prepare and process arrests for transportation that were helpful for the transporting officers as well as the Detention Officers receiving the arrests. As an added benefit, arrests which did not feel disrespected by the team were much more likely to cooperate with investigators and provide valuable intelligence. When this way of seeing and responding to others became normative, the team found that people resisted their methods less and were more likely to cooperative. Where before suspects who were interrogated by detectives were much more likely to complain about the way the members of the SWAT team had treated them instead of discussing the case, suspects became more engaging and shared valuable intelligence information with investigators. Predictably, the number of seizures and arrests increased. During a three-year period, the team seized approximately three-times the amount of guns, drugs and currency than in the preceding decade.

\section{Results}

The results speak for themselves. A $100 \%$ elimination of community complaints related to tactical search warrant operations was accompanied by a three-fold increase in productivity. Productivity refers to guns and drugs taken off the streets in Kansas City. As an example: from January of 1999 through December of 2007 the 1910 squad seized $\$ 478,860.00$ of United States Currency, at an annual average of approximately $\$ 53,207.00$ per year. During the 2008 calendar year, the 1910 squad seized $\$ 177,317.00$ of United States Currency. This equates to an increase of $271 \%$ from the previous years' (2007) seizures and $333 \%$ increase from the preceding nine years. The Executive Summary compiled in $2016^{23}$ for 1910 Squad, Kansas City, Missouri Police Department stated that the above-named Squad that have been the subject of the most complaints of any department within the police force have transformed to "the tip of the spear" regarding kinetic operations involving drug trafficking and the violent armed gangs who profit from that criminal enterprise. Earlier, in the period between 2004 to 2007 the Department received two to three filed complaints per month connected to activities made by the Squad, generating costs for the Department of thousands of dollars and hundreds of man hours in responding to the collateral damage inflicted by the Squad in making arrests there now was practically no complaint over the last five years. In addition to this the unit over a five year period, starting from 2008 onwards, the Squad recovered more drugs, guns and forfeited money than in the previous decade while not receiving a single complaint related to the execution of a search warrant. Merrell Bennekin, Deputy Executive Director of Community Complaints in Kansas City, Missouri, (Executive Director as of January 1,2017) observed this remarkable transformation. Mr. Bennekin described the results as "amazing" both in the reduction of costly complaints against the Department and in terms of getting more 
guns and drugs off the street. As a lawyer, Mr. Bennekin appreciated how the Squad's attention to both suspects and the community reduced the risk that criminal cases would be thrown out on a "technicality". On the one hand, the team deserves credit for these results, but the people of Kansas City merit equal recognition. Collaborative results hinge upon a collective way of seeing people and challenges that enables the effective employment of Peelian Principles. Nevertheless, it was impossible to predict the way in which this novel working strategy would impact complaints about the team's work. After all, the team was still engaged in the same type of kinetic work breaking down doors, throwing flash bangs, destroying property and even shooting the occasional dog. Whereas before the team registered the highest number of community complaints in the organization, this strategic (mindset) shift led to the complete elimination of complaints against the team members. The SWAT team, once infamous for complaints, managed to discharge their assignments for over six years without a single complaint during a search warrant service.

\section{Conclusion}

An emotive dichotomy exists between expressing "aggressiveness" and demonstrating "respectfulness." Elements of the public assume that the police must be aggressive when responding to all dangerous criminal behaviour. The key is that, while working to be very tough on crime, police must do so in a manner that takes into consideration the humanity of those people with whom they interact. Respect for humanity is particularly relevant for officer safety and effectiveness regarding those who are arrested and prosecuted. The police ought to deal with dangerous criminal behaviour aggressively yet need to do so without making bias triggering judgments about the character of those that commit the crimes. When officers judge people as "less than" officers are more likely to miss subtle precursors to violent or aggressive behaviour. ${ }^{4}$ Being judgemental also causes police to ignore the needs of the community and opens the door for general mistreatment at the hands of the police. Being judgemental also carries the implication that the police should place a higher value on their personal perspectives and look past the needs of the community. This way of working within the criminal justice system opens the door for mistreatment of external participants (both criminals and citizens) at the hands of the police.As indicated above, in the execution of their duty, the actions of police officers can be tough. The Kansas City SWAT team and through them the KC Police department, learned that people's opinion about the police are shaped primarily not by what the police do, but on how people feel they are being regarded by the officers during the interaction. Unconditional respect is a powerfully transformative concept. Most people want to feel like they are valued at some level, and they are primed to recognize judgemental attitudes and nonverbal indications of contempt. They generally feel unsafe when they feel disrespected, and the resulting uneasiness may aggravate situations that are already tense and uncertain by their very nature. The change of mindset needed to achieve high trust levels within the community is rooted in a fundamental shift in the way officers perceive themselves in relation to their basic mission and those they serve and protect. Modern policing was formed upon a basis of communication and trust between the public and police, yet over time a failure to appreciate the increasing complexity in society in general helped the policing culture drift away from the notion that they are the guardians of democracy. The challenges of a dangerous and complex operating environment have caused some individuals to adopt a more dichotomous view "Us against them - we are fighting a war". Some research confirms the above notion, among them Sherman (1997), who demonstrated that disrespect, from police towards suspects and other citizens, correlated with people being less willing to comply with the law. He also found that "Hiring more police to provide rapid 911 responses with unfocused, random patrol, and reactive arrests does not prevent serious crime" (Sherman 1997, p. 1). Also, the revised edition of Association of Chief Police Officers (ACPO) contains the same message: that the world of protest has changed and that police practice must change to meet those changes (ACPO 2010). ${ }^{12}$ stated that "In other words, the success of dialogue units depends not just on what they do, but on what they are seen to do and how this is interpreted within the crowd prevention" (p. 4). Dixon sums it up: "What we need is a new policing, not the old 'professionalism' dressed up with tactics, technology, and rhetoric". ${ }^{6}$ Sherman concludes that there is a need of changing police style and that this is as important as focusing police methods (Sherman, 1997). It requires integrity to take personal responsibility for the way one perceives and responds to the actions of other individuals. Moreover, it requires courage to evaluate honestly how one may be part of those problems that one perceives and complains about in other individuals. Consistent integrity and courageousness fosters the character necessary to rise to the current challenges and respond to all members of the public with Unconditional Respect. Unconditional Respect honours Sir Robert Peel's principles and illumines the progression towards an enlightened law enforcement. ${ }^{24,25}$ The way forward, within the reciprocal determination of individual interactions, past all the confusing and charged labels such as 'warrior', 'guardian' or 'sheepdog' offers a foregone necessity. Adopting "unconditional respect" will influence not only the individual officer improving credibility, and confidence, but also improve safety and effectiveness. Moreover, adopting "Unconditional Respect" will improve organizational effectiveness, efficiency, morale and communication. As a result of this, the so well needed trust and relationship between police officers and the public will be able to grow and thereby secure the willing cooperation of the public that, stated in Sir Robert Peels principles, are so important for effective policing.

\section{Acknowledgments}

None.

\section{Conflicts of interest}

None.

\section{References}

1. Sharp EB.The dilemma of drug policy in the United States. HarperCollins College Publishers, USA. 1994. p.1-186.

2. Rahr S, Rice SK. From warriors to guardians: Recommitting American police culture to democratic ideals. New Perspectives in Policing Bulletin. Department of Justice, National Institute of Justice, USA.2015. p.1-16.

3. Definition of policing by consent. UK Government Policing by consent, USA. 2012

4. Colwell JL, Huth C. Unleashing the power of unconditional respect. CRP Press, USA.2010. p.1.

5. President's Task Force on 21st Century Policing. Final report of the President's task force on 21st century policing. Office of Community Oriented Policing Services, USA.2015.p.1-116.

6. Dixon D. Beyond Zero tolerance. Paper presented at the 3rd National outlook symposium on crime in Australia, Mapping the boundaries of Australia's criminal justice system, Australian Institute of Criminology, Australia.1999. p.1-25. 
7. Weisburd DL, Eck JE. What can police do to reduce crime, disorder and fear? The Annals of the American Academy of Political and Social Science.2004;593(1):42-65.

8. Bratton WJ, Griffiths W, Mallon R, et al. Zero Tolerance: Policing a free Society. The IEA Health and Welfare Unit,UK.1997.p.1-159.

9. La Vigne NG, Lachman P, Rao S, et al. Stop and Frisk: Balancing crime control with community relations. Office of Community Oriented Policing Service, USA.2014.p.1-68.

10. Wiley SA, Slocum LA, Esbensen FA. The unintended consequences of being stopped or arrested: An exploration of the labelling mechanisms through which police contact leads to subsequent delinquency. Criminology.2013;51(4):927-966.

11. Geller A, Fagan J, Tyler T, et al. Aggressive policing and the mentalhealth of young urban men. Am J Public Health.2014;104(12):2321-2327.

12. Gorringe H, Stott C, Rosie M.Dialogue police, decision making, and the management of public order during protest crowd events. Journal of Investigative Psychology and Offender Profiling.2012;9(2):111-125.

13. Holgersson S, Knutsson J. Dialogue policing a means for less collective violence? In:Madensen T \& Knutsson J (Eds.), Crime Prevention Studies: Preventing Collective Violence. Willan Publishing, USA. 2010.

14. Knutsson J.Advancing policing by using, producing and diffusing evidence. In: Knutsson J \& Tompson L (Eds.), Advances in evidencebased policing. Routledge, UK.2017.

15. Lawrence Lightfoot S Respect: An exploration. Perseus Books, USA 2000 .
16. Langdon SW. Conceptualizations of respect: Qualitative and quantitative evidence of four (five) themes. J Psychol.2007;141(5):469-484.

17. Rigby K, Mak AS, Slee PT. Impulsiveness, orientation to institutional authority, and gender as factors in self-reported delinquency among Australian adolescents. Personality and Individual Differences.1989;10(6):689-692.

18. Tarry H, Emler N. Attitudes, values, and moral reasoning as predictors of delinquency.British Journal of Developmental Psychology.2007;25(2):169-183.

19. Tyler TR, Blader SL. Cooperation in groups: Procedural justice, social identity and behavioural engagement. Psychology Press, USA.2000.

20. Lalljee M, Laham SM, Tam T.Unconditional respect for persons: A social psychological analysis. Gruppe. Interaktion. Organisation. Zeitschrift für Angewandte Organisationspsychologie (GIO). 2007;38(4):451- 464.

21. The outward mindset: Seeing beyond ourselves. Berret-Koeler Publishers, USA.2010

22. Van Horne P, Riley J. Left of bang: How the Marine Corps' combat hunter program can save your life. Black Irish Books, USA.2014.p.1-228.

23. Moore R.Executive summary of 2016 for 1910 Squad. Missouri Police Department, USA.2016.

24. Mc Chrystal S, Collins T, Silverman D, et al.Team of teams: New rules of engagement for a complex world. Penguin Publishing Group, USA, 2015.p.1-304.

25. Peel R. Robert Peel's Principles of law enforcement 1829. USA.1829.p.1. 